\title{
Concurrent Reactivation of Herpes Simplex and Varicella Zoster Viruses Confirmed by the Loop-Mediated Isothermal Amplification Assay
}

\author{
Tsukane Kobayashi $^{\mathrm{a}} \quad$ Akiko Yagami $^{\mathrm{a}}$ Kayoko Suzuki $^{\mathrm{c}}$ \\ Tetsushi Yoshikawa $^{\mathrm{b}}$ Kayoko Matsunaga ${ }^{a}$ \\ Departments of a Dermatology and ${ }^{b}$ Pediatrics, Fujita Health University School of \\ Medicine, Toyoake, and ' Department of Dermatology, Kariya Toyota General Hospital, \\ Kariya, Japan
}

\section{Key Words}

Loop-mediated isothermal amplification · Herpes simplex virus · Varicella zoster virus . Herpes simplex $\cdot$ Herpes zoster $\cdot$ Concurrent reactivation

\begin{abstract}
Concurrent reactivation of herpes simplex and varicella zoster viruses is rare. Here, we describe the case of an elderly patient with herpes labialis and herpes zoster manifesting as a right-side facial eruption with vesicles and crusting. The loop-mediated isothermal amplification (LAMP) assay demonstrated the presence of both herpes simplex virus type 1 and varicella zoster virus in swab samples taken from the face, which was confirmed by real-time $P C R$, suggesting concurrent reactivation of both viruses. The use of the LAMP assay in the present case indicates its usefulness in the diagnosis of atypical herpes infections.
\end{abstract}

(c) 2014 S. Karger AG, Basel

\section{Introduction}

Cutaneous infections by herpes simplex virus (HSV) and varicella zoster virus (VZV), both of which belong to the alpha subfamily of herpesviruses, are relatively common. After the primary infection, both HSV and VZV remain latent in the ganglia and may reactivate. Herpes labialis and herpes zoster have been estimated to occur in approximately $20-40 \%$ 
and $10-20 \%$ of the population, respectively. Simultaneous occurrence of both HSV and VZV has rarely been reported [1-8].

We have used the loop-mediated isothermal amplification (LAMP) assay to diagnose herpesvirus infection. The LAMP assay is a nucleic acid amplification method that can be used for the rapid and highly accurate detection of viral infections [9]. In this assay, the reaction is performed at $63-65^{\circ} \mathrm{C}$ for $60 \mathrm{~min}$, after which large amounts of amplification products are obtained. The amplification products are cloudy, so the presence of amplification is assessed by real-time turbidimetry. Enomoto et al. [10] and Okamoto et al. [11] examined the accuracy of LAMP in the diagnosis of HSV and VZV in skin samples, reporting that the sensitivity of LAMP remained unchanged even if samples were tested directly without DNA extraction. The sensitivity and specificity of the LAMP assay for HSV are reportedly similar to those of conventional viral isolation culture, but the sensitivity of LAMP for HSV is slightly lower than that of real-time PCR [12]. On the other hand, the sensitivity and specificity of the LAMP assay for VZV are similar to those of real-time PCR [11]. Clinical usefulness of the LAMP assay for the diagnosis of cutaneous herpesvirus infections have been reported [13].

Here, we report a patient with concurrent reactivation of HSV-1 and VZV in whom HSV1 and VZV were detected in facial lesions by the LAMP assay.

\section{Case Report}

A 69-year-old man, with a background of recurrent outbreaks of herpes labialis approximately once every 2 years and childhood varicella, noticed vesicles on the lower lips. Five days later, a skin eruption developed on the right side of his face. Although he had no history of atopic dermatitis, Kaposi varicelliform eruption with secondary bacterial infection was suspected at another hospital, so he was treated with oral acyclovir and levofloxacin for 2 days. The patient subsequently presented to our outpatient clinic for consultation after the lack of symptomatic improvement.

On examination, erythema and small vesicles were present on the right side of the face in the dermatome innervated by the maxillary branch of the trigeminal nerve; the dorsum nasi, philtrum and upper lip were also affected. Crusting of these lesions was observed, and the right eyelids were red and swollen. Small vesicles were also noted at the bottom of the lower lip (fig. 1). Vesicles with red halos were scattered on the trunk and extremities. Laboratory investigations revealed an elevated level of C-reactive protein of $2.4 \mathrm{mg} / \mathrm{dl}$, suggesting a mild inflammatory reaction; however, other blood tests, including immunoglobulin levels and HIV antibody results, were either normal or negative. No evidence of immunological dysfunction was seen. A small number of coagulase-negative staphylococci were identified on bacterial culture of a swab taken from a skin lesion.

The differential diagnosis included disseminated herpes zoster, varicella, herpes simplex and impetigo. We performed the LAMP assay (Eiken Chemical, Tokyo, Japan) using swab samples taken from the following areas: an erosion on the right cheek, vesicles on the upper and lower lips (fig. 1; arrows 1, 2 and 3) and a vesicle with a red halo on the right thigh. HSV1 and VZV were detected by LAMP in samples taken from all 3 sites on the face, and VZV was detected in the sample taken from the vesicle on the right thigh. LAMP results were confirmed by real-time PCR (table 1). Serologically, HSV-1- and VZV-specific IgG were positive. Based on these findings, the patient was diagnosed with facial herpes simplex and disseminated herpes zoster. 
The patient was treated with acyclovir at $750 \mathrm{mg} /$ day for 7 days and cefcapene pivoxil at $300 \mathrm{mg} /$ day due to the possibility of secondary bacterial infection. After 7 days of treatment, the facial swelling improved and all facial vesicles had crusted. The eruption on the trunk and extremities also became crusted. Postherpetic neuralgia or ocular lesions did not complicate disease resolution.

\section{Discussion}

In the present case, vesicles were seen in the dermatome innervated by the maxillary branch of the trigeminal nerve and on the lower lip, and the eruption extended beyond the midline. Reactivation of both VZV and HSV was suspected as the clinical appearance of the eruption was atypical for herpes zoster.

Some evidence suggests that HSV and VZV may remain latent in the same nerve ganglion. In the study by Theil et al. [14] in which temporal bone samples were collected from cadavers at autopsy, PCR revealed the presence of both HSV-1 and VZV in the nerve ganglion of the facial and vestibular nerves. Giehl et al. [15] performed PCR in a large group of patients with normal immune function in whom VZV or HSV infection was suspected based on clinical findings. Both viruses were detected from the same site in only $1.2 \%$ of all cases, leading to the conclusion that simultaneous reactivation of both viruses at the same site is rare. The majority of these cases had a clinical diagnosis of herpes zoster involving the trigeminal nerve, most patients were $\geq 50$ years of age, and approximately two-thirds had a past history of herpes labialis. From these findings, it was concluded that VZV reactivated first, followed by HSV reactivation. Although our patient had similar characteristics (elderly, herpes zoster involving the trigeminal nerve and history of herpes labialis) to the subjects in the aforementioned study, the initial event was HSV reactivation as evidenced by the appearance of labial vesicles 5 days prior to the cheek eruption.

The clinical diagnosis of herpes simplex or herpes zoster is sometimes difficult with a clinical picture similar to that of impetigo and contact dermatitis, and may require laboratory confirmation. Current sensitive detection methods for HSV and VZV include viral isolation culture and DNA detection by nucleic acid amplification. However, these tests are relatively cumbersome and may not be readily available. In contrast, LAMP is sensitive even without DNA extraction; therefore, it represents a quick and economical method for the diagnosis of common alpha herpesvirus skin infections. In the present case, the result of the LAMP assay was congruent with that of real-time PCR, with the positive detection of both HSV-1 and VZV.

\section{Conclusion}

We reported a rare case of facial herpes infection in which HSV and VZV were detected at the same anatomical site and from the same lesions using the LAMP assay. This case suggests that the LAMP assay is useful in the rapid diagnosis of atypical herpes infections. 
Kobayashi et al.: Concurrent Reactivation of Herpes Simplex and Varicella Zoster Viruses Confirmed by the Loop-Mediated Isothermal Amplification Assay

\section{References}

1 Terasaki S, Kameyama T, Yamamoto S: A case of zoster in the 2nd and 3rd branches of the trigeminal nerve associated with simultaneous herpes labialis infection - a case report. Kurume Med J 1997;44:61-66.

2 Nikkels AF, Frère P, Rakic L, Fassotte M, Evrard B, De Mol P, Piérard GE: Simultaneous reactivation of herpes simplex virus and varicella-zoster virus in a patient with idiopathic thrombocytopenic purpura. Dermatology 1999;199:361-364.

-3 Gibney MD, Leonardi CL, Glaser DA: Concurrent herpes simplex and varicella-zoster infection in an immunocompromised patient. J Am Acad Dermatol 1995;33:126-129.

-4 Cupps TR, Straus SE, Waldmann TA: Successful treatment with acyclovir of an immunodeficient patient infected simultaneously with multiple herpesviruses. Am J Med 1981;70:882-886.

5 Curley MJ, Hussein SA, Hassoun PM: Disseminated herpes simplex virus and varicella zoster virus coinfection in a patient taking thalidomide. J Clin Microbiol 2002;40:2302-2304.

-6 Godet C, Beby-Defaux A, Landron C, Moal GL, Becq-Giraudon B, Agius G: Concomitant disseminated herpes simplex virus type 2 infection and varicella zoster virus primoinfection in a pregnant woman. Scand J Infect Dis 2005;37:774-776.

7 Park HH, Lee MH: Concurrent reactivation of varicella zoster virus and herpes simplex virus in an immunocompetent child. J Korean Med Sci 2004;19:598-600.

8 De Vivo C, Bansal MG, Olarte M, Grossman ME: Concurrent herpes simplex type 1 and varicella-zoster in the V2 dermatome in an immunocompetent patient. Cutis 2001;68:120-122.

-9 Notomi T, Okayama H, Masubuchi H, Yonekawa T, Watanabe K, Amino N, Hase T: Loop-mediated isothermal amplification of DNA. Nucleic Acids Res 2000;28:e63.

10 Enomoto Y, Yoshikawa T, Ihira M, Akimoto S, Miyake F, Usui C, Suga S, Suzuki K, Kawana T, Nishiyama Y, Asano Y: Rapid diagnosis of herpes simplex virus infection by a loop-mediated isothermal amplification method. J Clin Microbiol 2005;43:951-955.

11 Okamoto S, Yoshikawa T, Ihira M, Suzuki K, Shimokata K, Nishiyama Y, Asano Y: Rapid detection of varicellazoster virus infection by a loop-mediated isothermal amplification method. J Med Virol 2004;74:677-682.

-12 Sugiyama H, Yoshikawa T, Ihira M, Enomoto Y, Kawana T, Asano Y: Comparison of loop-mediated isothermal amplification, real-time PCR, and virus isolation for the detection of herpes simplex virus in genital lesions. J Med Virol 2005;75:583-587.

13 Kobayashi T, Yagami A, Suzuki K, Ihira M, Yoshikawa T, Matsunaga K: Clinical utility of loop-mediated isothermal amplification assay for the diagnosis of common alpha herpesvirus skin infections. J Dermatol 2013;40:1033-1037.

14 Theil D, Derfuss T, Strupp M, Gilden DH, Arbusow V, Brandt T: Cranial nerve palsies: herpes simplex virus type 1 and varicella-zoster virus latency. Ann Neurol 2002;51:273-274.

15 Giehl KA, Müller-Sander E, Rottenkolber M, Degitz K, Volkenandt M, Berking C: Identification and characterization of 20 immunocompetent patients with simultaneous varicella zoster and herpes simplex virus infection. J Eur Acad Dermatol Venereol 2008;22:722-728.

Table 1. Results of LAMP and real-time PCR

\begin{tabular}{|c|c|c|c|c|}
\hline & \multicolumn{2}{|l|}{ HSV1 } & \multicolumn{2}{|l|}{$\mathrm{VZV}$} \\
\hline & LAMP & $\begin{array}{l}\text { real-time PCR, } \\
\text { copies } / \mathrm{ml}\end{array}$ & LAMP & $\begin{array}{l}\text { real-time PCR, } \\
\text { copies/ml }\end{array}$ \\
\hline Erosion on the right cheek & + & $212,397,300$ & + & $79,956,678,400$ \\
\hline Vesicle on the upper lip & + & $443,756,050$ & + & $11,851,276,000$ \\
\hline Vesicle on the lower lip & + & 648,750 & + & $17,077,676,800$ \\
\hline Vesicle on the right thigh & - & 0 & + & $2,981,181,200$ \\
\hline
\end{tabular}




\section{Case Reports in Dermatology}

Kobayashi et al.: Concurrent Reactivation of Herpes Simplex and Varicella Zoster Viruses Confirmed by the Loop-Mediated Isothermal Amplification Assay

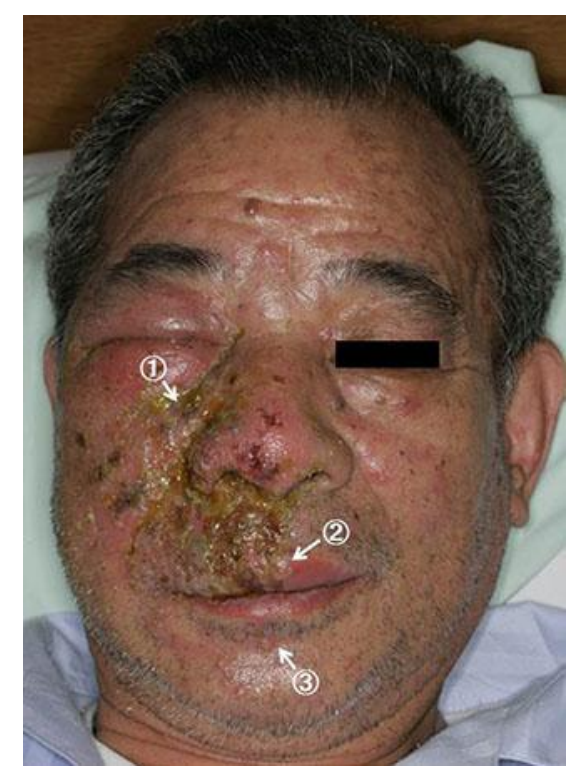

Fig. 1. Clinical appearance of the patient's face at the first visit. The right eyelids were swollen. The right infraorbital area, cheek and lips were erythematous with erosions and crusting. Blisters were present on the upper lip and below the lower lip. 